\title{
Las bases materiales del desarrollo económico en España (1860-2016). Un estudio desde el metabolismo social*
}

\section{The Material Basis of Spain's Economic Development (1860-2016). A Socio-Metabolic Perspective}

Juan Infante-Amate

Universidad de Granada

Eduardo Aguilera

Universidad Politécnica de Madrid

Jaume Vila

Ángel Sanjuán

Felipe Oropesa

Manuel González de Molina

Universidad Pablo de Olavide

\section{Resumen}

En este trabajo presentamos una serie histórica de los indicadores de extracción, comercio y uso de materiales recogidos en la metodología de la contabilidad del flujo de materiales, un sistema armonizado internacionalmente para cuantificar el uso de recursos a nivel regional. Con los resultados obtenidos analizamos la transición al metabolismo industrial en España, observando: (i) un rápido aumento en el consumo de materiales (se cuadruplican en términos per cápita) y en la transición al uso de recursos no renovables, especialmente entre 1960 y 2007; (ii) transición de exportador neto (hasta c. 1930) a importador neto (desde c. 1960); (iii) continuada caída de la intensidad material; y (iv) fuerte caída en el uso de materiales tras la Gran Recesión.

Palabras clave: contabilidad del flujo de materiales, metabolismo social, economía ecológica, desmaterialización, objetivos del desarrollo sostenible, antropoceno.

Clasificación JEL: O13, N53, N54.

\section{Abstract}

In this work, we provide a historical series of the material extraction, trade, and use indicators contained within the Material Flow Accountability methodology-which is an internationally standardized system to quantify resource use at a regional level. Drawing on our results, we examine the transition to industrial metabolism in Spain, highlighting: (i) a quick increase in material consumption (400\% per capita growth) and in the transition to non-renewable resource use, especially between 1960 and 2007; (ii) a transition from net exporter (until ca. 1930) to net importer (desde ca. 1960); (iii) a persistent decrease in material intensity; and (iv) a sudden drop in material use after the Great Recession.

Keywords: material flow accounting, social metabolism, ecological economics, dematerialization, sustainable development goals, antrhopocene.

* Artículo realizado con la financiación del proyecto RTI2018-093970-B-C33 del Ministerio de Ciencia, Innovación y Universidades y de la Beca Leonardo a Investigadores y Creadores Culturales 2019 de la Fundación BBVA (la Fundación BBVA no se responsabiliza de las opiniones, comentarios y contenidos incluidos en el proyecto y/o los resultados obtenidos del mismo, los cuales son de total responsabilidad de sus autores). 


\section{Introducción}

En los últimos dos siglos, con el auge de la sociedad industrial, la humanidad ha multiplicado a niveles sin precedentes su capacidad de extraer, procesar y usar materiales para satisfacer sus necesidades, lo que ha permitido que la mayor parte de la población mundial alcance cotas inéditas de bienestar (Krausmann et al., 2009; Smil, 2016; Pinker, 2018). Hoy podemos recorrer con facilidad largas distancias, usar y desechar decenas de productos diariamente, construir con rapidez grandes edificios e infraestructuras, o consumir regularmente alimentos exóticos (Smil, 2016).

Sin embargo, el aumento en la apropiación y uso de recursos materiales está conllevando, a su vez, graves impactos en el medioambiente que ponen en cuestión la viabilidad de este modelo de desarrollo. Existen sobradas evidencias que sostienen que se están superando ciertos «umbrales de seguridad» a partir de los cuales podemos afrontar riesgos impredecibles que pueden amenazar nuestro modo de vida (Rockström et al., 2009). Por este motivo, uno de los grandes retos futuros de nuestra sociedad es conseguir desacoplar los niveles de desarrollo y de bienestar del uso de recursos naturales. No en vano, este propósito aparece de manera directa o indirecta en cinco de los Objetivos del Desarrollo Sostenible, la nueva agenda rectora de la política global hasta 2030, aprobada por las Naciones Unidas en 2015. En particular, el objetivo 12.2 alude a «lograr la gestión sostenible y el uso eficiente de los recursos naturales» y el objetivo 8.4, sobre crecimiento económico, a «mejorar [...] la producción y el consumo eficientes de recursos mundiales y procurar desvincular el crecimiento económico de la degradación del medioambiente» (Schandl et al., 2018).

Para comprender cómo las sociedades humanas han logrado alcanzar los niveles de bienestar material actuales, pero también para poder implementar con más rigor políticas que permitan minimizar los impactos ambientales, es necesario generar información fiable y adecuada sobre el uso de recursos naturales. Una de las metodologías más extendidas para este propósito es la contabilidad del flujo de materiales (CFM), un sistema contable armonizado internacionalmente para cuantificar la extracción, el comercio y el consumo de materiales en una unidad territorial determinada (Eurostat, 2018). ${ }^{1}$ Esta metodología agrega el uso total de materiales en cuatro grandes categorías (biomasa, combustibles fósiles, minerales metálicos y minerales no metálicos). Aunque este nivel de agregación impide evaluar impactos específicos o por subsector productivo, es una herramienta muy adecuada para comprender el uso general de recursos, la tipología de materiales demandados, su evolución a lo largo del tiempo, establecer comparativas regionales bajo una metodología armonizada, estudiar la relación comercial física entre países y analizar la intensidad material de una economía, esto es, el grado de recursos necesarios para generar cada unidad

${ }^{1}$ Además del uso de materiales en los sistemas económicos, esta metodología también contempla en estudio de (i) los output al medio natural, esto es, los vertidos, emisiones y otros desechos materiales generados; así como de (ii) los stocks, esto es, de los materiales que no son consumidos anualmente, sino que permanecen en forma de infraestructuras, maquinaria o equipamiento similar (Eurostat, 2018). En este trabajo, no obstante, solo analizaremos los inputs materiales de la economía española. 
de PIB. Este tipo de indicadores han permitido trascender las lecturas parciales sobre el cambio económico de largo plazo, que habitualmente solo ponen el foco en los bienes y servicios con valor de mercado. Así, los estudios de CFM con perspectiva histórica han servido para abonar las teorías sobre la transición socioecológica o la transición sociometabólica, esto es, sobre el cambio en los patrones de extracción y uso de energía y materiales que tienen lugar entre la sociedad y su medioambiente (Infante-Amate et al., 2017; Haberl et al., 2019).

En este trabajo presentamos la primera estimación histórica, en serie anual, sobre la CFM para el caso de España. Hasta la fecha, Carpintero (2005) había publicado una serie análoga para el periodo 1955-2000, e Infante-Amate et al. (2015) para el periodo 1860-2010, aunque este último trabajo únicamente aportaba información para 16 puntos temporales y no distinguía todos los grupos de productos en el comercio exterior y el consumo. Por su parte, el Instituto Nacional de Estadística (INE, 2020) y Eurostat (2020) publican estimaciones de la CFM en España desde 1995. A nivel internacional, tanto Naciones Unidas (2020) como WU Vienna (2019) ofrecen estimaciones para la mayoría de países del mundo, pero solo desde 1970. En perspectiva de largo plazo, incluyendo series de más de un siglo de duración, únicamente existen estudios para el caso de Inglaterra (Schandl \& Shulz, 2002), Austria (Krausmann et al., 2008), Checoslovaquia (Kuskova et al., 2008), Japón (Krausmann et al., 2011), Estados Unidos (Gierlinger et al., 2012), Francia (Magalhaes et al., 2019) y Rusia (Krausmann et al., 2016). Nuestro estudio se une, por tanto, a esta reducida lista de países y permite alargar temporalmente las series publicadas por las agencias estadísticas.

Los resultados obtenidos nos permiten abordar los siguientes objetivos: (i) cuantificar la extracción de materiales por tipo de recurso, lo que nos informa de la evolución y la tipología de impactos ambientales y explica muchos de los conflictos socioambientales que han tenido lugar en el país; (ii) cuantificar el comercio internacional en términos físicos, con lo que podemos analizar la evolución de las relaciones materiales con otros países, el balance comercial físico, la dependencia exterior y las dinámicas de «intercambio ecológico desigual»; (iii) estimar los cambios históricos en el consumo de materiales y estudiar su evolución; (iv) calcular la intensidad material de la economía española, esto es, la relación entre crecimiento económico y consumo de materiales para analizar si la economía española se ha desmaterializado; (v) a través de un análisis de descomposición, evaluar los determinantes del cambio en el uso de materiales, distinguiendo la población, la riqueza y el cambio tecnológico (análisis IPAT); (vi) por último, aportar una visión de largo plazo sobre la «transición sociometabólica» en España en perspectiva comparada, esto es, sobre la transición del régimen agrario al industrial y sobre qué implicaciones tuvo sobre el crecimiento económico y sobre los impactos en el medioambiente.

Después de presentar una breve síntesis metodológica, dedicamos un capítulo a cada uno de los seis objetivos citados. 


\section{La contabilidad del flujo de materiales. Notas metodológicas}

La metodología de la contabilidad del flujo de materiales se desarrolló a finales de la década de 1990 para superar las limitaciones propias de la Contabilidad Económica Nacional, a la hora de informar sobre los impactos ambientales de los sistemas económicos (Fischer-Kowalski et al., 2011). Poco después, esta metodología fue asumida por los principales organismos internacionales para guiar su política ambiental, especialmente los objetivos de desacoplamiento del crecimiento económico del uso de recursos (Krausmann et al., 2017; Schandl et al., 2017). Entre los organismos que la incorporaron a sus estadísticas oficiales están Eurostat, Naciones Unidas o la OCDE, así como por otros organismos nacionales como el INE, que la ha integrado dentro de sus cuentas ambientales.

La CFM diferencia tres grandes grupos de indicadores. Por un lado, la extracción doméstica de materiales (ED), esto es, la cantidad total de materiales apropiados dentro de las fronteras territoriales del país analizado. Se consideran todos los que entran al sistema económico, tengan o no valor de mercado. Igualmente, se considera la apropiación indirecta de algunos recursos (por ejemplo, en el caso de los minerales se contabiliza el «mineral bruto» removido, no solo el contenido metálico). En segundo lugar, el balance comercial físico (BCF), estimado como las importaciones físicas menos las exportaciones físicas. Así, un balance positivo denota que el país es importador neto, y viceversa. Finalmente, la suma del ED y el BCF, resulta en el consumo doméstico de materiales (CMD), esto es, los materiales realmente consumidos por un país. Estas variables, asociadas a datos de población o PIB, generan otros indicadores auxiliares como el consumo doméstico por habitante o la intensidad material, medida esta última como las toneladas consumidas por unidad de PIB generado.

Cada variable analizada se estima para una amplia gama de productos materiales que, para su presentación y su análisis, se agregan en cuatro grandes categorías: biomasa, combustibles fósiles, minerales metálicos y minerales no metálicos.

Para la reconstrucción histórica de estos indicadores es necesario utilizar diferentes fuentes y registros históricos. En el caso de la extracción de biomasa, entre 1961 y la actualidad, tomamos la información de FAOSTAT, ya que permite una descarga más rápida y el procesamiento de los datos es más sencillo. Entre $c .1935$ y 1961, utilizamos las series retrospectivas publicadas en los Anuarios de Estadística Agraria, que aportan información para la mayoría de los cultivos. Aunque ambas fuentes no cubren la totalidad de cultivos producidos en España, la muestra seleccionada cubre más de un $95 \%$ de la producción en materia fresca. El resto de cultivos lo completamos utilizando los datos de González de Molina et al. (2020), que sí cubren todos los cultivos con datos decenales entre $c .1900$ y 2008. Los años vacíos se interpolan linealmente. Entre $c .1890$ y 1935 usamos la información del GEHR (1991), aunque los datos de superficie solo están disponibles desde 1898. Esta base de datos presenta algunos huecos para ciertos cultivos que hemos estimado interpolando linealmente los rendimientos y la superficie. Para $c .1890$ también usamos la información de los 
Avances de la Junta Consultiva Agronómica para el cereal (JCA, 1891a), la viña (JCA, 1891b) y el olivar (JCA, 1891c). Para 1860 tomamos los datos de superficie y producción recogidos en Garrabou y Sanz (1995) y en Gallego (1986) para los principales grupos de cultivos. Asumimos que la proporción de cada cultivo dentro de su grupo (por ejemplo, el trigo dentro de la categoría de cereales) es similar en 1860 que en $c .1900$. Entre 1860 y 1890, para evitar una estimación lineal, interpolamos modulando la serie con las precipitaciones anuales utilizando la correlación observada entre 1900 y 1930. Esa modulación anual está lejos de ser exacta, aunque estamos convencidos de que es más aproximada que una simple tendencia lineal. Todos los datos de extracción forestal provienen de Infante-Amate e Iriarte-Goñi (2017). Los de pesca provienen de Carreras y Tafunell (2005) y de las Estadísticas Pesqueras dentro del Anuario de Estadística Agraria.

La extracción del resto de minerales se toma de la Estadística Minera de Espa$\tilde{n} a$, publicada con diferentes nombres desde 1861. En este caso, algunos materiales, especialmente los de cantera, no siempre se han registrado completamente ya que buena parte de la extracción tenía lugar fuera del mercado y no era contabilizada. En estos casos solo utilizamos las estadísticas oficiales entre 1960 y la actualidad, cuando ofrecen valores más fiables. Para años anteriores calculamos la serie según la variación del consumo de cemento y el asfalto en aquellos materiales relacionados con su producción, siguiendo el criterio de Eurostat (2018) y, para el resto, o cuando no contamos con información de los citados productos, usamos la variación poblacional.

En el caso del comercio de materiales, desde 1962, tomamos la información de comercio internacional de UNCOMTRADE y de FAOSTAT, dos bases de datos globales publicadas por Naciones Unidas y FAO respectivamente que ofrecen la información online en un formato más accesible. Entre 1860 y 1961 utilizamos literatura secundaria y la Estadística de Comercio Exterior. En primer lugar, recopilamos series ya publicadas por otros autores. Estos trabajos ofrecen información para más de una veintena de productos clave que representan más del $70 \%$ del comercio físico ${ }^{2}$. En segundo lugar, recopilamos la información de los resúmenes de la Estadística de Comercio Exterior, que compila información para los principales productos del comercio internacional. Con estos dos pasos completamos casi el $90 \%$ del comercio físico en una serie anual que incluye entre 60 y 90 productos. Para el resto de productos solo tomamos los valores de los años terminados en cero desde la Estadística de Comercio Exterior. Los huecos se interpolan según la evolución de productos análogos.

La información del PIB se toma de Bolt (2014), y la de población de Carreras y Tafunell (2005) y del INE.

\footnotetext{
${ }^{2}$ Por ejemplo, en Carreras y Tafunell (2005) se ofrece información para casi una veintena de productos minerales y agrarios. En Infante-Amate (en preparación) se ofrecerán detalles más precisos sobre la elaboración de esta base de datos.
} 


\section{Extracción de materiales}

La gran transformación que ha tenido lugar en la economía física global en los dos últimos siglos se explica, esencialmente, por el formidable aumento de nuestra capacidad extractiva de los recursos materiales de la biosfera y la litosfera (Graedel et al., 2015; Smil, 2016). Más allá del aumento poblacional, que también ha contribuido al incremento en la demanda de materiales, la revolución tecnológica y el acceso a nuevas fuentes de energía explican el aumento sin precedentes del potencial de la apropiación humana de recursos naturales. La industria extractiva ha pasado de operar con «motores de sangre», esto es, con tracción humana y animal de escasa potencia, a utilizar maquinaria pesada que puede movilizar centenares de toneladas en pocas horas (Smil, 2016).

En el caso de España la extracción de materiales ha pasado de 15,8 millones de toneladas (Mt) en 1860 a 734,4 Mt en 2007, justo antes de la Gran Recesión (Gráfico 1). Durante ese periodo, la población se multiplicó por 2,8. Sin embargo, la extracción por habitante se cuadruplicó, pasando de 4,0 a 16,4 toneladas per cápita. Si bien es cierto que la extracción de materiales, tanto total como por habitante, venía creciendo desde el siglo XIX, su «Gran Aceleración» tuvo lugar a partir de la década de 1950. Entre 1860 y antes de la Guerra Civil, la extracción doméstica de materiales había crecido un $80 \%$, mientras que entre 1950 y 2007 se multiplicó por cinco (Gráfico 1a).

Además del formidable cambio en nuestra capacidad extractiva, observamos una transición en el tipo de materiales apropiados. En sociedades preindustriales la mayoría de la extracción estaba dominada por productos agrarios, forestales y pesqueros, esto es, por biomasa. Hacia mediados del siglo xIX representaba un $90 \%$ de la extracción material, mientras que el $10 \%$ restante estaba compuesto por una pequeña gama de minerales metálicos y de productos de cantera. Hoy en día, la biomasa apenas representa un $32 \%$ de la extracción total, habiendo alcanzado su mínimo histórico en 2015 con un $14 \%$. Esta caída, no obstante, solo ha tenido lugar en términos relativos, ya que la extracción total de biomasa ha seguido aumentando.

Esta transición en el tipo de extracción también es indicativa de la tipología de los impactos ambientales, así como de la conflictividad socioambiental asociada al extractivismo. En sociedades tradicionales, la conflictividad era esencialmente agraria, y estaba dominada por las protestas campesinas (Acosta et al., 2009). De la misma forma, los impactos ambientales se concentraban en el sector agrario, siendo los más recurrentes las pérdidas de suelo por erosión (Vanwalleghem et al., 2011), la minería de nutrientes (González de Molina et al., 2015) o la deforestación (Infante-Amate e Iriarte-Goñi, 2017). Sin embargo, a medida que aumentó la extracción de materiales abióticos emergieron nuevos impactos ambientales y, con ello, nuevos conflictos y nuevas formas de protesta. Entre 1860 y 1935, la extracción agraria solo aumentó un $42 \%$, un crecimiento incluso inferior al de la población (56\%), mientras que la extracción de combustibles fósiles se multiplicó por 21, la de minerales metálicos por 7 y la de minerales no metálicos por 4 . Durante este periodo empezaron 


\section{GRÁFICO 1}

\section{EXTRACCIÓN DOMÉSTICA DE MATERIALES EN MILLONES} DE TONELADAS (A) Y COMO PORCENTAJE (B)
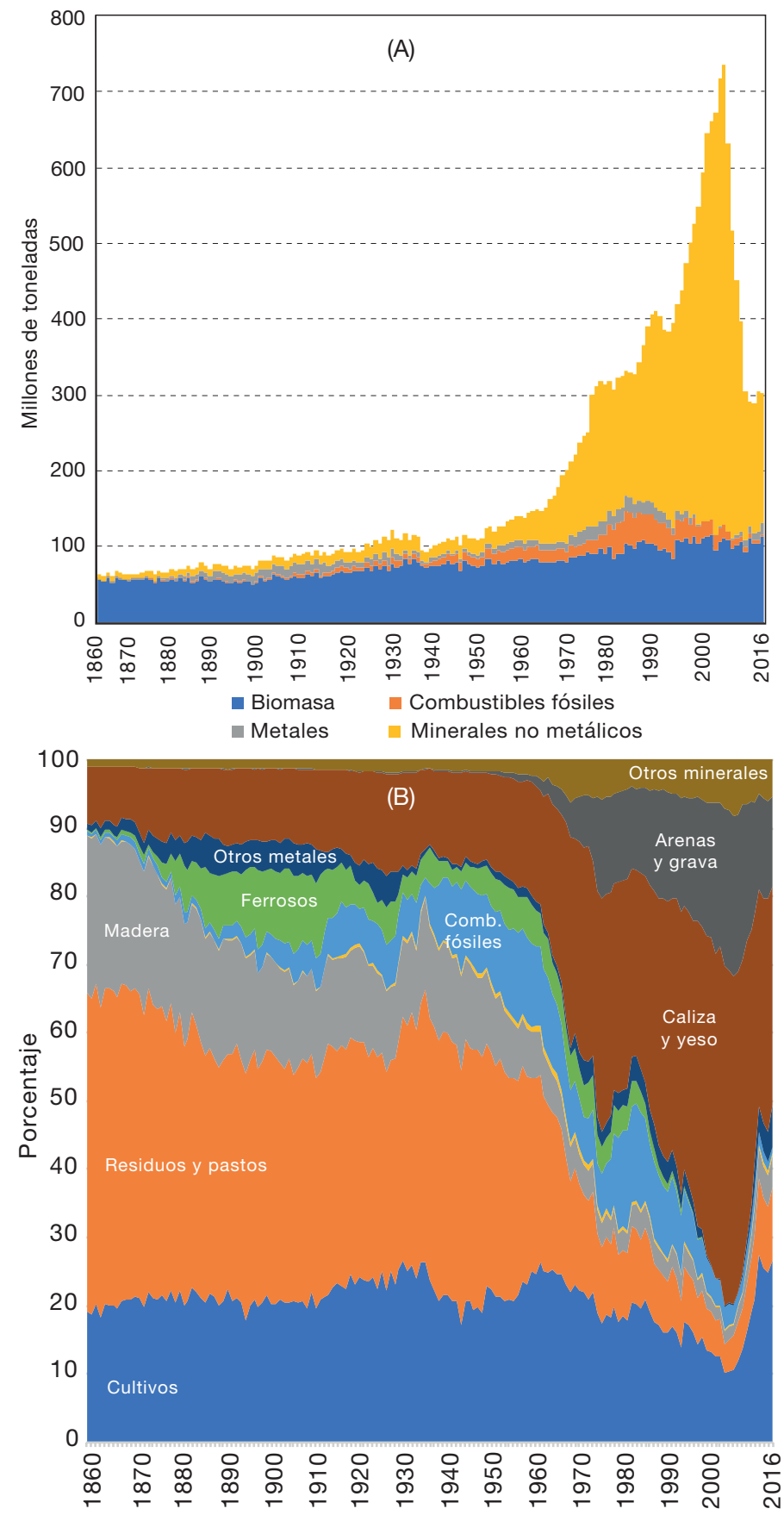

FUENTE: Elaboración propia. 
a documentarse nuevos conflictos vinculados al extractivismo minero y a las actividades industriales asociadas al procesamiento de nuevos materiales inorgánicos (Ferrero, 1994; Chastagnared, 2017; García Gómez \& Pérez Cebada, 2020). Igualmente, empezaron a generalizarse nuevos impactos ambientales como la contaminación en el agua, los suelos y el aire, principalmente debidos a la proliferación de la minería metálica (Pérez Cebada, 2014). La extracción de metales ferrosos pasó de poco más de 100.000 toneladas en 1860 a casi alcanzar los 10.000 .000 en los albores del siglo xx. España, no en vano, fue de los principales productores y exportadores de mineral de hierro, también de cobre, a nivel mundial. Estas extracciones, cuyos impactos eran locales, tenían como destino el comercio internacional, ya que la mayor parte era exportada.

Durante la «Gran Aceleración», que en España tuvo lugar desde mediados de siglo hasta la crisis de 2008, la extracción minera estuvo dominada por los productos de cantera y, en consecuencia, por el auge de los sucesivos booms urbanísticos, lo que a su vez capitalizó buena parte de la conflictividad social y la emergente conflictividad ambiental en el país desde la década de 1960, incluyendo importantes casos de corrupción, que han sacudido la política española hasta nuestros días (Naredo, 2003). Durante este periodo, también cobró cierta importancia la extracción de combustibles fósiles, especialmente de lignito, cuya producción creció en la década de 1960, sustituyendo a la hulla, que había dominado la producción carbonífera desde el xIx. Sin embargo, su dimensión en el conjunto de los materiales extraídos siempre fue menor, y su consumo dependió históricamente, como veremos más abajo, de las importaciones.

\section{La dimensión física del comercio internacional}

Otro rasgo distintivo del «régimen sociometabólico industrial» es el aumento del comercio internacional, esto es, del intercambio de recursos naturales entre países. En sociedades tradicionales, la mayoría del transporte se basaba en la tracción animal, lo que limitaba sustancialmente la capacidad de movilizar materiales. Por ello, las sociedades preindustriales eran, al decir de Rolf Peter Sieferle (2001), «islas de escasez» abocadas a producir domésticamente la mayoría de bienes y servicios que requerían. El transporte de larga distancia apenas se limitaba a productos de poco peso y gran valor como las especias, los textiles o las piedras preciosas (Martínez Alier et al., 2009). El desarrollo de medios de transporte movidos por combustible fósiles como el ferrocarril, el barco de vapor, el transporte terrestre motorizado y, después, la aviación, permitieron aumentar los flujos de materiales intercambiados entre países distantes.

En el caso de España, el comercio de materiales empezó a crecer a partir de mediados del siglo XIX, durante la conocida como «Primera Globalización» (Gráfico 2). Entre 1860 y 1914 el crecimiento anual de las exportaciones fue del 5,3\% y el de las importaciones del 3,2\%. Esto es, en términos materiales se acentuó el perfil exportador de la economía española. La cesta de productos exportados estuvo dominada hasta $c .1950$ por minerales metálicos (principalmente por mineral de hierro) y por biomasa; mientras que los combustibles fósiles, especialmente el carbón, 
fueron el principal material de importación. Después, el intercambio de materiales con terceros países protagonizó un periodo de fuertes oscilaciones debido a las caídas asociadas a la I Guerra Mundial, el crack del 29 y, las más acusada, durante la Guerra Civil y la posguerra. A partir de la década de 1950 el comercio volvió a crecer de manera acelerada hasta 2007, momento a partir del cual las importaciones, no así las exportaciones, cayeron bruscamente. El crecimiento anual durante la «Segunda Globalización» (consideramos 1950 a 2007) alcanzó el 5,8\% en el caso de las exportaciones y un espectacular 7,2\% en el de las importaciones, unas cantidades superiores a las observadas durante la primera oleada. Tras la autarquía, el cambio en la política económica tras el Plan de Estabilización conllevó importantes transformaciones en las relaciones internacionales, que se acentuaron con el aperturismo hacia la Unión Europea, los EE. UU. y las políticas de reconversión industrial. La liberalización del comercio provocó entradas masivas de todo tipo de productos a precios más baratos que los producidos dentro del país (Tena, 2005). No solo de petróleo, un recurso del que España apenas tenía dotaciones; sino también de bienes manufacturados e incluso productos agrarios. Aunque España guarda la imagen de país agroexportador, lo cierto es que desde $c .1960$ sus importaciones agrarias son muy superiores a las exportaciones en términos físicos (Gráfico 2c). Esto se debe esencialmente a la importación de granos cuyo destino es la alimentación animal (González de Molina et al., 2020).

¿Qué implicaciones tuvo el aumento del comercio físico a nivel económico? Por un lado, facilitó que muchos países, entre ellos España, sortearan la escasez relativa de ciertos recursos cuyas dotaciones domésticas eran muy limitadas, lo cual permitió romper el cuello de botella del crecimiento, especialmente en los países en que no disponían de combustibles fósiles.

Por otro lado, el auge le comercio permitió la externalización de impactos ambientales indeseados a terceros países, así como promocionar consumos opulentos en base a la apropiación de materiales de fronteras lejanas. De esta forma, se generalizaron las dinámicas de «intercambio ecológico desigual», mediante el cual los países más ricos aumentaron su déficit exterior en términos materiales a la vez que mejoraban su relación real de intercambio (Hornborg, 1998). Muchos países ricos han desarrollado legislaciones laborales y ambientales muy garantistas a la vez que han externalizado la producción fuera de sus fronteras a países con exigencias más laxas. De esta forma, crean una ficción contable mediante la cual sus sistemas productivos son limpios y justos ocultando que sus patrones de consumo siguen siendo igualmente impactantes, puesto que contribuyen a la degradación ambiental y social en terceros países. No obstante, para analizar este fenómeno adecuadamente es necesario estimar y analizar los impactos incorporados en el comercio, esto es, aquéllos asociados a la producción de bienes que finalmente se exportan (Peters, 2008; Kander et al., 2017).

No obstante, resulta reduccionista asociar acríticamente países de altas rentas con importación neta de materiales, y viceversa. Aunque regiones como América Latina han sido históricamente suministradoras netas de recursos (Infante-Amate et al., 2020) y que la mayoría de países occidentales son demandantes netos (Krausmann et al., 2011; Magalhaes et al., 2019), especialmente los que tienen altas densidades 


\section{GRÁFICO 2}

\section{IMPORTACIONES (A), EXPORTACIONES (B) Y BALANZA COMERCIAL} FÍSICA (C)
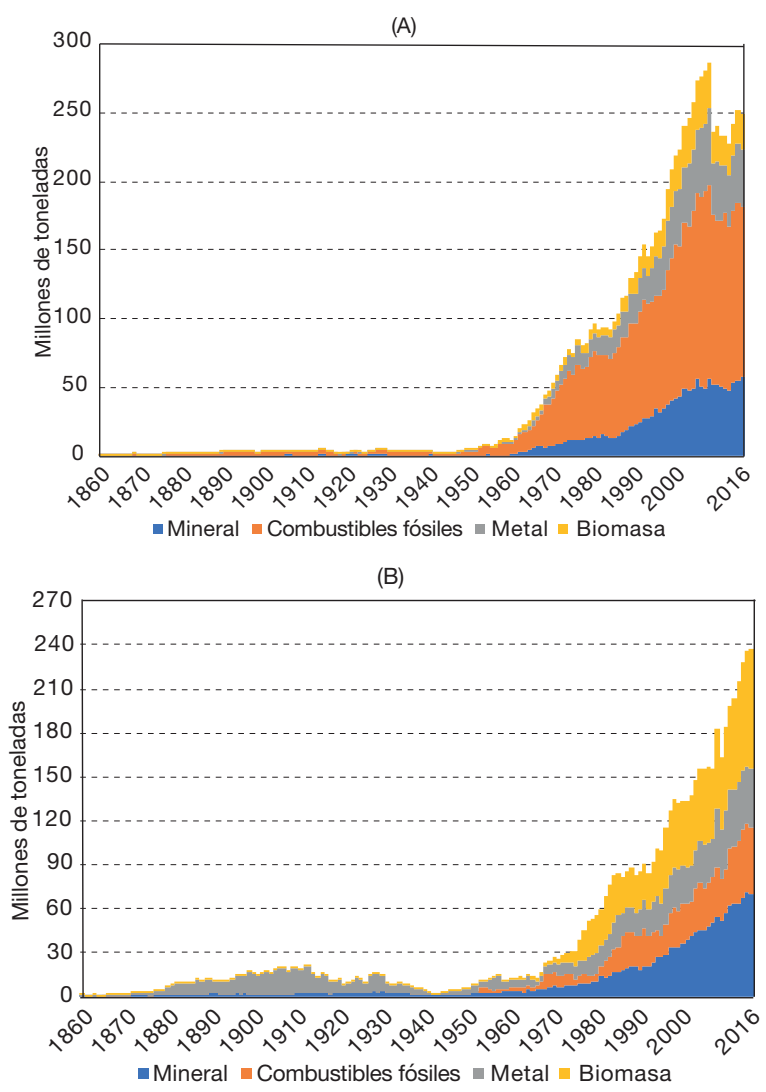

(c)

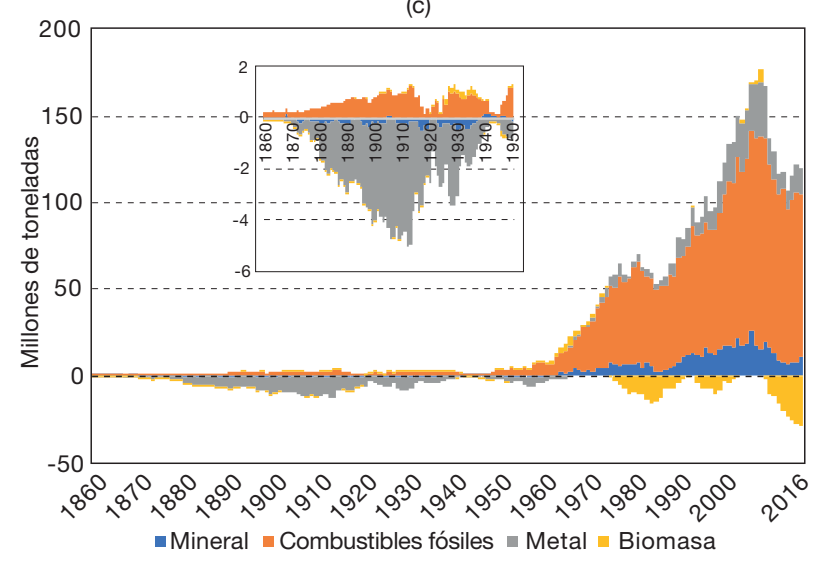

NOTA: Nótese que en la metodología de la CFM la balanza comercial física se estima como las importaciones menos las exportaciones.

FUENTE: Elaboración propia. 
poblacionales (Bruckner et al., 2012); existen muchas excepciones a esta norma. Países como EE. UU. o Inglaterra, arquetipos de países «hegemónicos» (o «centro») en los modelos interpretativos del «Sistema Mundo», han sido durante varias fases de su desarrollo reciente exportadores netos de recursos (Schandl \& Schulz, 2002; Gierlinger \& Krausmann, 2012; Kander et al., 2017).

En el caso de España, observamos que hasta la Guerra Civil el país jugó un papel periférico, siendo exportador neto de materiales con poco valor, sobre todo minerales metálicos y productos agrarios, al resto de Europa ${ }^{3}$. Esta tendencia cambió radicalmente desde mediados del siglo xx, cuando España empezó a revertir el signo de las relaciones materiales, mostrando balanzas positivas, especialmente debido a las importaciones de materiales de los países del «Sur Global», a los que ahora se externalizan impactos ambientales como la deforestación, el uso de tierra, las emisiones de gases de efecto invernadero o la contaminación de suelos y agua (Aguilera et al., 2020; González de Molina et al., 2020).

\section{Cambios en el consumo de materiales}

El auge del comercio internacional también permitió disociar a gran escala las actividades de producción y consumo. En sociedades preindustriales la mayoría del consumo se satisfacía con materiales apropiados localmente. Sin embargo, la posibilidad de establecer relaciones comerciales fluidas con otros territorios posibilitó que el consumo se completase en un porcentaje significativo con productos «exóticos». Así, los países con bajas dotaciones de recursos podían aumentar sus niveles de consumo a través del comercio, y viceversa.

En el caso de España el consumo de materiales ha pasado de 63,6 Mt en 1860 a 399,4 Mt en 2016, con un pico de 911,3 Mt en 2007. En términos per cápita, el consumo pasó de poco más de 4 tons en 1860 a más de 20 tons en 2007 (Gráfico 3a). Este incremento se debe tanto a la mejora de la capacidad extractiva, que explica el $75 \%$ del aumento en el consumo, como al comercio internacional, que explica el $25 \%$ restante. Dicho de otra forma, la gran expansión del consumo de materiales que ha tenido lugar en el último siglo y medio se debe en gran medida a las mejoras tecnológicas que nos han permitido expandir nuestra apropiación de recursos, pero también a los recursos que nos llegan de otros países.

En el Gráfico 3b mostramos el peso del comercio internacional en el consumo doméstico de materiales. A mediados del siglo XIX las importaciones jugaban un papel insignificante en el consumo doméstico, mientras que hoy en día suponen más del $20 \%$ del consumo. El peso de las importaciones totales sobre el consumo doméstico de

${ }^{3}$ En términos energéticos fue importador, ya que fue importador neto de combustibles fósiles, mientras que era exportador neto de materiales no energéticos. Igualmente, fue importador neto de tierra, ya que los productos agrarios que importaba (por ejemplo, cereales) tenían una huella territorial mayor que los que exportaba (olivar, viña, frutales...) (Infante-Amate et al., 2018). 
materiales pasó de un 5\% a mediados del siglo XIx hasta un 30\% en la década de 1980. Tras un par de décadas de estabilización, volvieron a crecer aceleradamente tras la crisis de 2008 hasta alcanzar el $60 \%$. Dicho de otra forma, de los materiales consumidos dentro de la economía española, casi dos terceras partes provienen del extranjero.

Las tendencias históricas de consumo también muestran otro hecho interesante: mientras que el consumo de biomasa por habitante se ha mantenido relativamente estable entre 2,5 y 3,5 toneladas, el consumo de abióticos ha pasado de 0,5 y 17,5, con un crecimiento más acelerado a partir de $c$. 1950. En otras palabras, el gran aumento en el consumo de materiales se explica por el creciente uso de los recursos apropiados del subsuelo, y no tanto por los recursos obtenidos de la tierra.

Una condición necesaria para explicar el crecimiento económico moderno fue, según Wrigley (2016), la superación del «imitante fotosintético» propio de las sociedades preindustriales. Esto ocurrió cuando pasamos de un modelo productivo dependiente de los productos que ofrecía la tierra, que se generaban en base a un flujo anual limitado por la capacidad de fotosíntesis, a hacerlo con los productos del subsuelo. La posibilidad de extraer materiales desde stocks cuya disponibilidad no estaba limitada por un flujo productivo anual como ocurría con la biomasa, facilitó la entrada masiva de grandes cantidades de energía y materiales a la economía física global. Así, el transporte (animales alimentados de biomasa) o la producción industrial (dependiente de la leña o el carbón vegetal) dejaron de depender de materias primas con una disponibilidad limitada y con fluctuaciones anuales debidas a factores climáticos. Así, el proceso de «expansión vertical», siguiendo la analogía de Barbier (2011), fue un elemento decisivo para explicar el aumento en el consumo de recursos a escala planetaria, pero también para desencadenar impactos ambientales a gran escala que hoy ponen en cuestión nuestro modelo de desarrollo.

En el caso de España, cada habitante, en promedio, consumía 4 toneladas en 1860, de las que 3,6 eran de productos bióticos, 0,05 combustibles fósiles, 0,04 metales y 0,38 productos de cantera. En el régimen sociometabólico industrial (con datos de 2007) cada habitante consume 2,8 toneladas de productos agrarios, 3,1 de combustibles fósiles, 0,7 de metales y 13,7 de productos de cantera.

La estabilidad en el consumo de productos bióticos se explica por factores que han empujado al alza y otros que han empujado a la baja el consumo, de manera que han terminado compensándose. Por un lado, la mayor disponibilidad de alimentos, la transición a una dieta más cárnica biomasa y el aumento del desperdicio alimentario, han tirado al alza el consumo por habitante (González de Molina et al., 2020). Sin embargo, la transición socioecológica hacia materiales inorgánicos ha supuesto la reducción del consumo de ciertos productos bióticos como la leña en la industria o el pasto para animales de tracción.

Por último, otra característica en relación al cambio en los patrones de consumo durante la transición sociometabólica industrial tiene que ver con la diversidad de materiales utilizados. En sociedades preindustriales la mayoría de los productos consumidos se limitaban a un reducido grupo de productos agrarios domésticos y a un conjunto, todavía menor, de productos minerales. A mediados del siglo XIX una decena de productos agrarios, entre los que destacan la leña, el pasto, el trigo, la cebada 


\section{GRÁFICO 3}

CONSUMO DOMÉSTICO DE MATERIALES POR HABITANTE (A) Y PORCENTAJE DE LAS IMPORTACIONES NETAS SOBRE EL CONSUMO DOMÉSTICO DE MATERIALES (B)

(A)

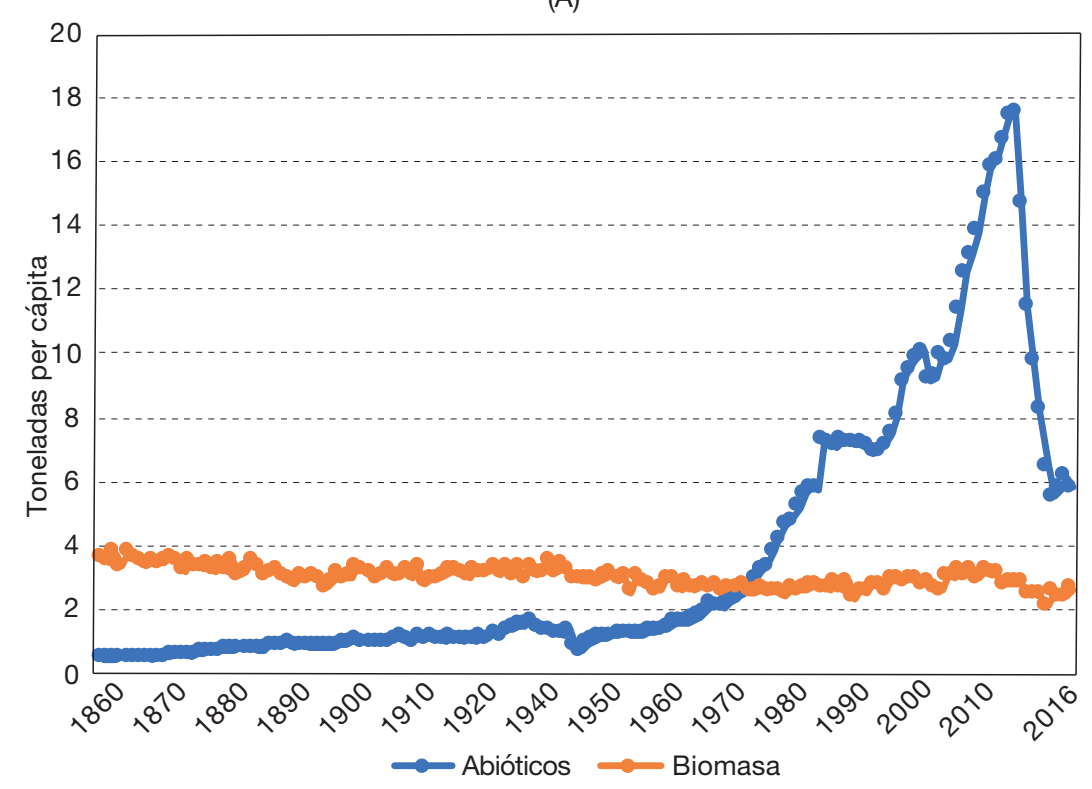

(B)

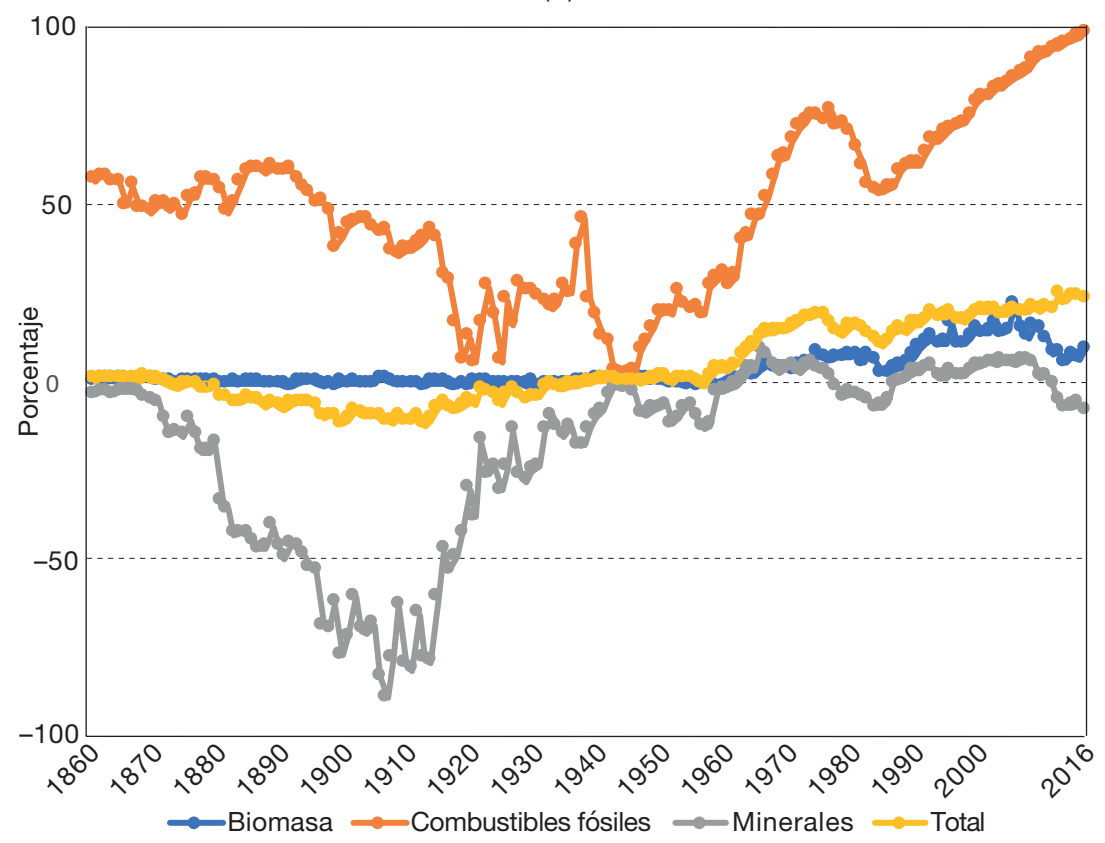

FUENTE: Elaboración propia 
y algunos frutales, representaban casi dos terceras partes de todos los materiales consumidos, mientras que la piedra caliza y otros productos de cantera representaba más del $90 \%$ de todos los minerales extraídos. La transición sociometabólica nos convirtió en omnívoros desde un punto de vista material, según la expresión de Greenfield y Graedel (2013). Hoy en día se consumen centenares de productos sin que ninguno, salvo el petróleo, tenga un peso muy representativo en el consumo total.

\section{6. ¿Desmaterialización o rematerialización?}

Entre los grandes retos de nuestro tiempo, tal y como se recoge en los planes de actuación de los principales gobiernos e instituciones del mundo, entre ellos los Objetivos del Desarrollo Sostenible de Naciones Unidas, está la «desmaterialización» de la economía. ¿Estamos consiguiéndolo?

Antes de responder a esta pregunta es necesario empezar haciendo una aclaración metodológica. La literatura distingue dos tipos de desmaterialización, la débil o relativa, y la fuerte o absoluta (De Bruyn \& Opschoor, 1997; Ruffing, 2007). La primera, alude al uso de recursos por unidad de PIB generado que, siguiendo la metodología de la CFM, se suele cuantificar a través del indicador de la «Intensidad Material», esto es, el CDM dividido por el PIB. Así, si el PIB crece a mayor ritmo que el consumo de materiales, podemos decir que la economía se está desmaterializando en términos relativos (o débiles). Por otro lado, la desmaterialización fuerte o absoluta simplemente tiene en cuenta la evolución del consumo de materiales, independientemente de cómo se comporte el PIB. La primera, por tanto, nos informa de si el crecimiento económico se desacopla del consumo de materiales. La segunda, evidencia si realmente estamos estabilizando o reduciendo nuestro consumo de materiales en términos absolutos, esto es, cómo evoluciona el perfil metabólico de la economía.

¿Qué ha pasado en España durante el último siglo y medio? En el Gráfico 4a mostramos la intensidad material de la economía española entre 1860 y la actualidad. Observamos una tendencia generalmente decreciente, lo que indica una caída de la intensidad material de la economía. Si hacia mediados del siglo XIX se requerían c. 1,5 kg para producir cada $\$$ de PIB (precios contantes de 2011), en la actualidad se requieren poco más de $0,2 \mathrm{~kg}$ por $\$$. Existen algunas excepciones a esta tendencia como la Guerra Civil y la posguerra, cuando la economía se deprimió más que el uso de recursos; o las décadas de 1960 y 1970, en las que el gran crecimiento económico fue acompañado por un uso de recursos más acelerado aún. Durante estos periodos la desmaterialización relativa se frenó e incluso se revirtió. El balance general, en cualquier caso, muestra que la economía española ha mejorado sustancialmente su eficiencia material en términos relativos. Sin embargo, como hemos visto más arriba, su CDM no ha dejado de crecer, por lo que no podemos hablar de una desmaterialización absoluta o fuerte de la economía, ya que esta consume cada vez más recursos, 


\section{GRÁFICO 4}

INTENSIDAD MATERIAL, MEDIDA COMO CONSUMO DOMÉSTICO DE MATERIALES ENTRE EL PIB A PRECIOS CONSTANTES DE 2011 (A). EVOLUCIÓN DEL CONSUMO DOMÉSTICO DE MATERIALES Y DE LA INTENSIDAD MATERIAL CON REFERENCIA 1860=1 (B)

(A)

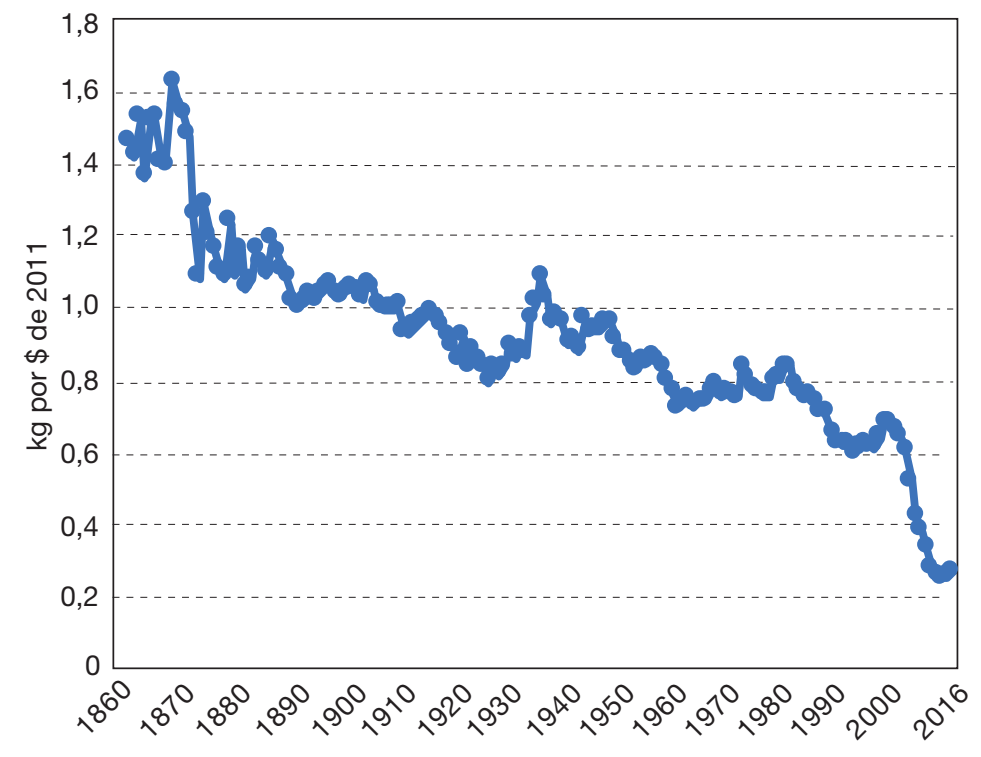

(B)

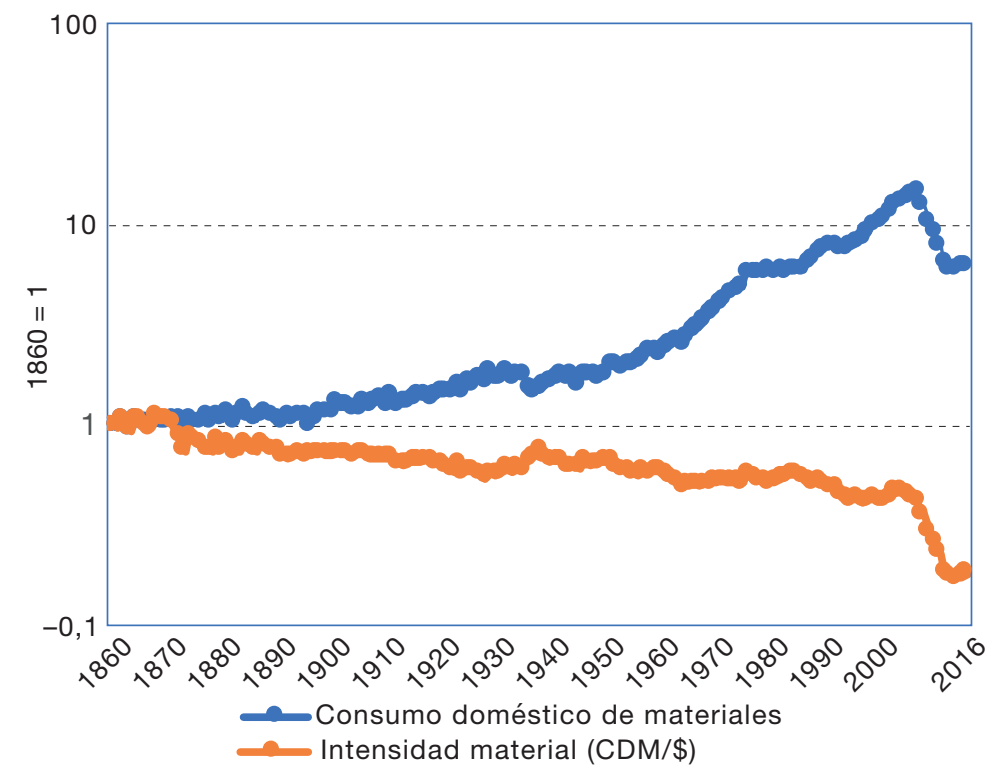

FUENTE: Elaboración propia. 
tanto a nivel general como en términos per cápita. No obstante, debido a la Gran Recesión, entre 2008 y 2014 se observó una fuerte caída en el consumo y, por tanto, una desmaterialización absoluta, que aparentemente es transitoria. Aún falta perspectiva histórica para saber si es un hecho coyuntural o un cambio de tendencia.

A modo de síntesis: tomando como referencia el año 1860 (1860=1), la intensidad material, que es indicativa de la desmaterialización relativa, ha caído a 0,18 ; mientras que el CMD, indicativo de la desmaterialización fuerte, ha subido a 6,2 (Gráfico 4b). La economía crece más rápido que el uso de recursos, pero el uso de recursos, y sus impactos asociados, no han dejado de crecer, con cortas excepciones como la Guerra Civil y la Gran Recesión.

\section{Determinantes del cambio}

En este apartado analizamos los factores determinantes del aumento en el consumo de recursos, para lo que realizamos un análisis de descomposición aditivo tipo IPAT siguiendo la propuesta de Ang (2005). Dicho de otra forma, cuantificamos qué parte del impacto ambiental (I), en este caso medido como el consumo directo de materiales, se explica por el aumento poblacional $(\mathrm{P})$, por el aumento en la riqueza (A), o por la eficiencia material, atribuible esencialmente al cambio estructural y al cambio tecnológico (T). Más población y más renta empujan al alza el consumo de materiales, y viceversa, mientras que las mejoras tecnológicas lo empujan a la baja. El reto está en determinar qué peso ha tenido cada una de estas variables en la variación del consumo a lo largo del tiempo.

Schandl et al. (2017) realizaron un ejercicio similar para las principales regiones del mundo entre 2000 y 2010. Según sus resultados el aumento en el consumo de materiales que tuvo lugar a nivel global durante esa década se debió en un $30 \%$ al aumento poblacional, en un $67 \%$ al aumento de la renta, y en un $2 \%$ a la pérdida de eficiencia material, generalmente causada por la caída en la eficiencia tecnológica. Esto es, el aumento poblacional sigue presionando sobre el uso de recursos materiales, pero el principal factor que explica el aumento en el consumo es el aumento de la riqueza, sobre todo debido al auge de una clase media global, especialmente en el sudeste asiático, que ha aumentado con creces su consumo. Sorprendentemente, la tecnología no ha supuesto un factor de reducción en el uso de materiales, sino de aumento. Esto no se debe a que haya habido un retroceso en la técnica, sino que una cantidad muy importante del procesamiento de ciertos materiales se ha desplazado a países con tecnologías menos eficientes como China, donde, por ejemplo, se requieren más toneladas de materias primas para producir la misma cantidad de acero. En consecuencia, las tendencias globales esconden diferencias regionales: en Asia, el gran crecimiento en el consumo de materiales se explica casi por igual por los tres factores PAT, esto es al crecimiento población, al aumento de la renta y la pérdida de eficiencia tecnológica debida al cambio estructural de su producción mientras que en los países más ricos, entre ellos los europeos y los norteamericanos, la eficiencia 
material sí ha generado importantes ahorros en el consumo mientras que la población y la riqueza han seguido empujando el crecimiento ${ }^{4}$.

¿Qué ha pasado en el caso de España? En el Gráfico 5 resumimos los principales resultados del modelo IPAT. Si analizamos todo el periodo de estudio en su conjunto, esto es, entre 1860 y la actualidad, observamos que el aumento de la renta ha sido el principal factor explicativo, aunque el crecimiento poblacional también ha tenido un peso relevante. Las mejoras en la eficiencia han permitido ahorros en el consumo que habrían logrado paliar sobradamente el aumento poblacional, sin embargo, el aumento de la renta y la consecuente expansión de la demanda, anularon el efecto del cambio tecnológico. En una perspectiva de largo plazo asistimos a un claro ejemplo de «efecto rebote»o «paradoja de Jevons», ya que las mejoras de eficiencia no han logrado reducir el consumo, sino que han propiciado un mayor acceso a los recursos $\mathrm{y}$, por tanto, un aumento del consumo.

\section{GRÁFICO 5 \\ ANÁLISIS DE DESCOMPOSICIÓN ADITIVO PARA CUANTIFICAR EL PESO DEL CAMBIO EN LA POBLACIÓN, LA RENTA Y LA EFICIENCIA MATERIAL EN EL CONSUMO DE MATERIALES. NÓTESE QUE EL CONSUMO EQUIVALE A LA SUMA DE POBLACIÓN, RENTA Y EFICIENCIA}
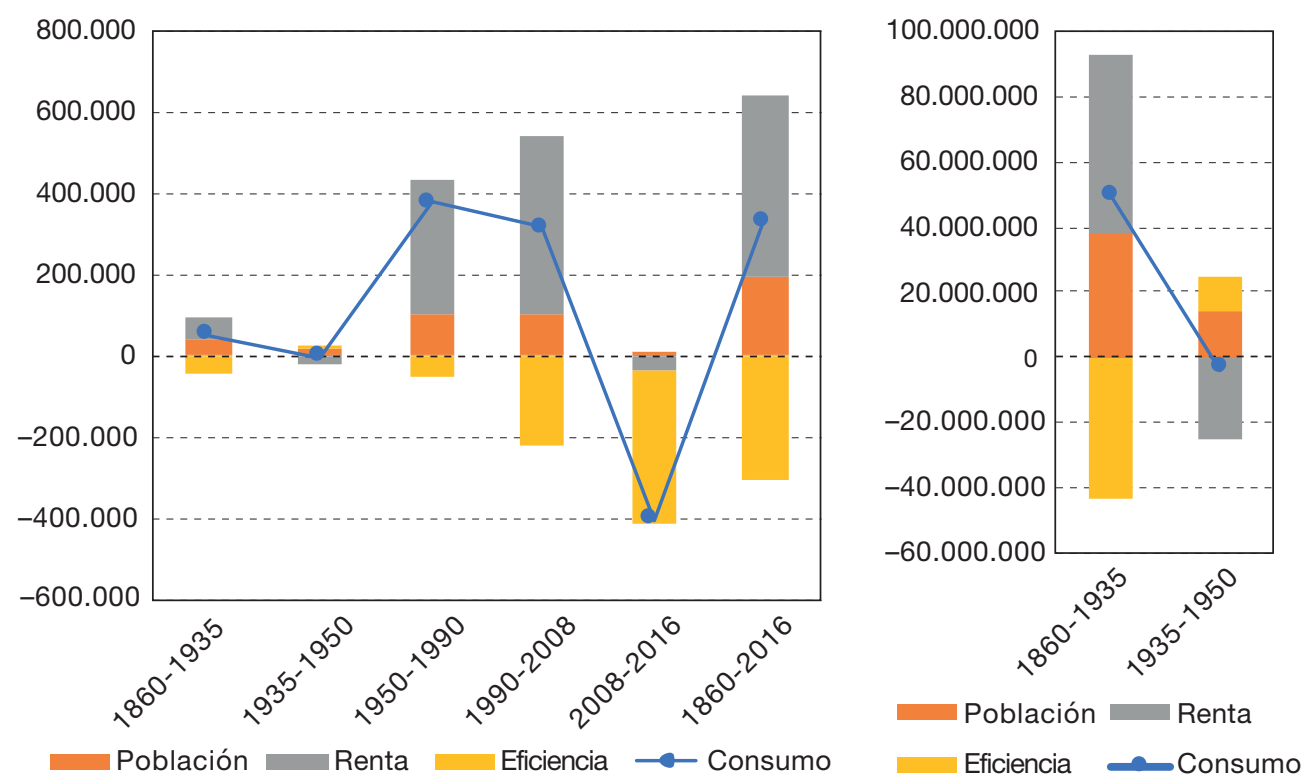

FUENTE: Elaboración propia

\footnotetext{
${ }^{4}$ Esto es así desde un punto de vista «territorial» o desde una contabilidad basada en la producción. Si utilizamos métricas basadas en el consumo.
} 
El papel de cada variable ha cambiado a lo largo del periodo estudiado. Así, si en lugar de analizar el cambio general en el último siglo y medio, analizamos periodos concretos, encontramos resultados diferentes. Durante la primera globalización y las primeras fases de la industrialización, la población (aumentando el consumo), la renta (aumentando el consumo) y la eficiencia material (disminuyendo el consumo) tuvieron un impacto análogo. Durante la Guerra Civil y la posguerra el consumo cayó ligeramente debido a la caída de las rentas, a pesar de que la población siguió creciendo y que la pérdida de la eficiencia material que, durante este periodo, presionó el consumo de recursos al alza. Entre 1950 y 2008, observamos un crecimiento descomunal en el consumo de materiales explicado principalmente por el aumento de la riqueza y, en menor medida, por el aumento poblacional. No obstante, hasta 1990 la eficiencia material provocó una reducción en el consumo muy liviana mientras que esta fue mucho mayor a partir de 1990. Tras la crisis de 2008, el país vivió un proceso inédito, con una reducción en el consumo de materiales muy superior incluso al registrado durante la Guerra Civil y la posguerra. La caída de 2008 no solo es atribuible a la reducción de la renta, como ocurrió durante la guerra, sino que también se explica por la mejora en la eficiencia material, que, a su vez, no se debió a la mejora tecnológica sino al cambio estructural de la economía española, en la que perdieron peso actividades con alta intensidad material como el sector de la construcción.

\section{La transición material de la economía española}

Según Haberl y Fischer-Kowalski (2007), podemos distinguir tres grandes regímenes sociometabólicos a lo largo de la historia: el cazador-recolector, el agrario y el industrial. En este trabajo, para el caso de España, hemos analizado la transición del régimen agrario al régimen industrial, caracterizada por un fuerte un aumento en el consumo de materiales, por la transición al uso de recursos no renovables y por el aumento de los intercambios de materiales.

En un contexto preindustrial, la economía española, como la del resto del mundo, era esencialmente dependiente de los productos de la tierra para satisfacer sus necesidades. Como hemos apuntado, a mediados del siglo XIX, 9 de cada 10 toneladas consumidas provenían de la tierra, cuyos productos satisfacían la mayor parte de las necesidades humanas (Kander et al., 2015; Wrigley, 2016). Además de la alimentación humana, la biomasa se utilizaba para la vestimenta (fibras vegetales y animales), como combustible doméstico e industrial (leña y otros residuos), para el transporte (a través del alimento animal) y, parcialmente, como material de construcción (madera). En sistemas dependientes de la tierra la única forma de aumentar la producción pasaba por: (i) expandir la frontera cultivada, lo que resultaba cada vez más difícil en zonas con altas densidades de población, como era el caso de la mayor 
parte de Europa; o (ii) intensificar el uso del suelo, esto es, aumentar la producción por unidad de superficie, una estrategia igualmente de difícil implementación en países como España, con condiciones agroclimáticas desfavorables y con suelos agotados tras siglos de extracción (González de Molina et al., 2015). De hecho, ya en el siglo XIX, observamos que España disponía de mucha menos biomasa que otros países industrializados, lo que no solo hacía tener una dieta diferente, sino que limitaba la capacidad de transporte, de tracción o de la producción industrial. En este contexto de «restricción malthusiana», la manera de sortear los límites al crecimiento propios de las sociedades agrarias fue la «expansión vertical», esto es, obtener del subsuelo materiales sustitutivos (Barbier, 2011; Wrigley, 2016).

La conquista del subsuelo se produjo, en esencia, por la transición a fuentes energéticas no renovables como el carbón, el petróleo y, finalmente, el gas natural. La particularidad de estas nuevas fuentes de energía es que eran más versátiles y más eficientes que las tradicionales y, además, se podía disponer de ellas a gran escala, sin depender de un flujo productivo anual. Su uso, unido a nuevos desarrollos tecnológicos como la máquina de vapor, el motor de explosión o la industria química (por ejemplo, con la síntesis industrial de amoniaco), permitieron aumentar el potencial extractivo del resto de materiales. De hecho, muchos trabajos ponen de manifiesto una importante correlación entre uso de combustibles fósiles y crecimiento económico (Ayres \& Warr, 2010), aunque se observa cierto desacoplamiento desde las décadas finales del siglo xx (Kander et al., 2015).

La incorporación de materiales abióticos a la economía no fue un mero proceso aditivo, sino que implicó cambios estructurales en los sistemas productivos preexistentes. De hecho, uno de los rasgos destacados de la transición sociometabólica industrial ha sido el cambio funcional de los sistemas agrarios tradicionales, que pasaron de satisfacer la mayoría de las necesidades a centrarse en la producción de alimentos y materias primas (González de Molina \& Toledo, 2014). Cuando se analiza el impacto de la industrialización en la agricultura habitualmente se señala la adición de insumos externos (fertilizantes, pesticidas...) que permitieron aumentar los rendimientos; sin embargo, se pasa por alto que la industrialización también causó transformaciones de gran calado en la funcionalidad de la agricultura. Según nuestras estimaciones, en 1860 tan solo un $20 \%$ de la producción agraria española en términos físicos se destinaba directamente a la alimentación humana, mientras que en la actualidad más de un $60 \%$ tiene este destino.

En perspectiva comparada, la transición sociometabólica española ha seguido el mismo patrón que la mayoría de los países del mundo, aunque con ciertas particularidades asociadas a sus características geográficas y a su propio desarrollo histórico. Lamentablemente, solo contamos con evidencia empírica de largo plazo para un pequeño grupo de países occidentales con los que establecer un marco comparativo. Según la evidencia existente y los resultados obtenidos en este trabajo, los principales rasgos de la transición española serían los siguientes: 
- El consumo de materiales por habitante en la España preindustrial se situaba ligeramente por debajo del promedio global, y muy por debajo de países europeos de clima templado, con mayor productividad primaria, como Francia o Inglaterra, así como de países como Estados Unidos, con amplias fronteras agrícolas disponibles y altas dotaciones de recursos minerales. El aumento en el consumo de materiales propio de la transición socioecológica industrial llegó a España mucho después que a la mayoría de países industrializados, aunque antes que a los países emergentes. No obstante, la transición fue más abrupta que en la mayoría de países ya industrializados y no se detuvo hasta la crisis de 2008, lo que contrasta con lo ocurrido en el resto de economías desarrolladas en las que el consumo se estabilizó en la década de 1970 (Widenhofer et al., 2013) (Gráfico 5a). Este crecimiento tan espectacular hizo que España pasara de tener un consumo de materiales inferior al promedio global a principios de la década de 1970, a ser uno de los mayores consumidores del mundo en 2007. Este hecho diferencial se explica por haber empezado la transición más tarde pero también por el boom de la construcción, residencial, industrial y turística, dependiendo de las diferentes fases. El efecto de la crisis de 2008 fue, igualmente, más impactante que en el resto de países y volvió a empujar el consumo por debajo de la media global. Esta crisis afectó directamente al sector qué más había empujado el consumo de materiales al alza: la construcción. Su colapso ha hecho que el consumo de materiales siga hoy en día a niveles mucho bajos que los previos a la crisis. Hasta donde hemos podido documentar, la dimensión de la caída es solo asimilable a la que tuvo lugar en la Unión Soviética tras su desintegración (Krausmann et al., 2016).

- La transición al uso de recursos abióticos, determinante para explicar el crecimiento económico moderno, fue más tardía que en los países del entorno europeo, como han puesto de manifiesto otros estudios sobre transición energética (Kander et al., 2015), aunque también en este caso llegó antes que a los países del «Sur global». La lenta transición se debió a una menor dotación de recursos energéticos y a una política exterior proteccionista que limitó su importación (Sudrià, 1997). A principios del siglo XIX los niveles productivos en España ya eran inferiores que el de los países del entorno (Allen, 2011), luego es posible que el menor dinamismo económico ralentizase la transición en comparación a los países con mejores condiciones de partida. En España, la biomasa dejó de ser el material más consumido en 1964, mientras que esta transición se había dado mucho antes en Reino Unido (antes del XIX), en los EE. UU. (1913), en Japón (1923) o en Francia (1930). Es más, había tenido lugar incluso antes a nivel global (en 1956). No obstante, fue más tardía en países como China (1972), India (2000) o Brasil, donde aún no se ha completado (Gráfico 5b). 
En el proceso de transición sociometabólica, unos países han sido más dependientes del exterior que otros. En la actualidad, los países de altas rentas son más dependientes, pero, entre estos, son especialmente dependientes los países con altas densidades de población (Bruckner et al., 2012). Japón y los países europeos muestran perfiles más parasitarios que Estados Unidos, Canadá o Australia. También encontramos diferencias en perspectiva histórica. En las primeras fases de la transición sociometabólica, los países más ricos no siempre fueron importadores netos. Inglaterra tuvo balance equilibrado e incluso fue exportador neto de flujos ocultos, ya que destinaba muchos recursos a producir bienes que finalmente exportaba (Kander et al., 2017). Estados Unidos, debido a su vasta frontera agrícola y riqueza mineral, también fue exportador neto de recursos (Gierlinger \& Krausmann, 2012), como seguramente ocurrió con otros países ricos de gran tamaño como Canadá o Australia. Los países de industrialización más tardía como España o Checoslovaquia, también ejercieron un papel de suministradores netos de materias primas al resto de países industrializados, en el caso de España con productos mineros y agrarios. Sin embargo, durante la «Gran Aceleración», los países industrializados fueron incapaces de sostener sus transformaciones económicas con recursos endógenos y todos, incluso aquéllos que por diferentes motivos habían sido exportadores netos durante las primeras fases de la transición, acentuaron su papel parasitario mientras que desde el «Sur Global» aumentaban los flujos de materiales al resto del mundo (Schaffartzik et al., 2014; Infante-Amate et al., 2020) (Gráfico 6c). En el caso de España, cuya transición fue especialmente acelerada, el grado de dependencia externa es particularmente alto en comparación con los países del entorno. En el Gráfico 6d analizamos tanto el grado de dependencia (relación entre importaciones y exportaciones) como el volumen de la dependencia (balance comercial físico per cápita). Entre una muestra de los 28 países europeos más dependientes (excluimos aquellos que son exportadores netos como Suecia, Noruega o Polonia), más los Estados Unidos, observamos que España destaca como uno de los países más parasitarios. Sus importaciones son casi 3 veces superiores a las exportaciones y el balance por habitante supera las 2,2 toneladas al año. Estas cifras están muy por encima de la mayoría de los países del mundo y en el caso de Europa solo se superan ligeramente por Alemania, y en mayor medida por Irlanda e Italia. Este último país se revela como el país más dependiente del continente con unas importaciones que cuadriplican las importaciones y con un balance por habitante de 3,1 toneladas al año ${ }^{5}$.

\footnotetext{
5 Excluimos de este gráfico a Países Bajos y Bélgica ya que muestran volúmenes muy altos de comercio que esconde un alto porcentaje de reexportación que no podemos calibrar. No obstante, en ambos casos su grado de dependencia es menor que el de España, aunque el volumen sí que es claramente mayor.
} 


\section{GRÁFICO 6}

PERSPECTIVA COMPARADA. (A) EVOLUCIÓN DEL CONSUMO DOMÉSTICO DE MATERIALES (CDM). (B) DEL PESO DE LA BIOMASA SOBRE EL CONSUMO DOMÉSTICO DE MATERIALES
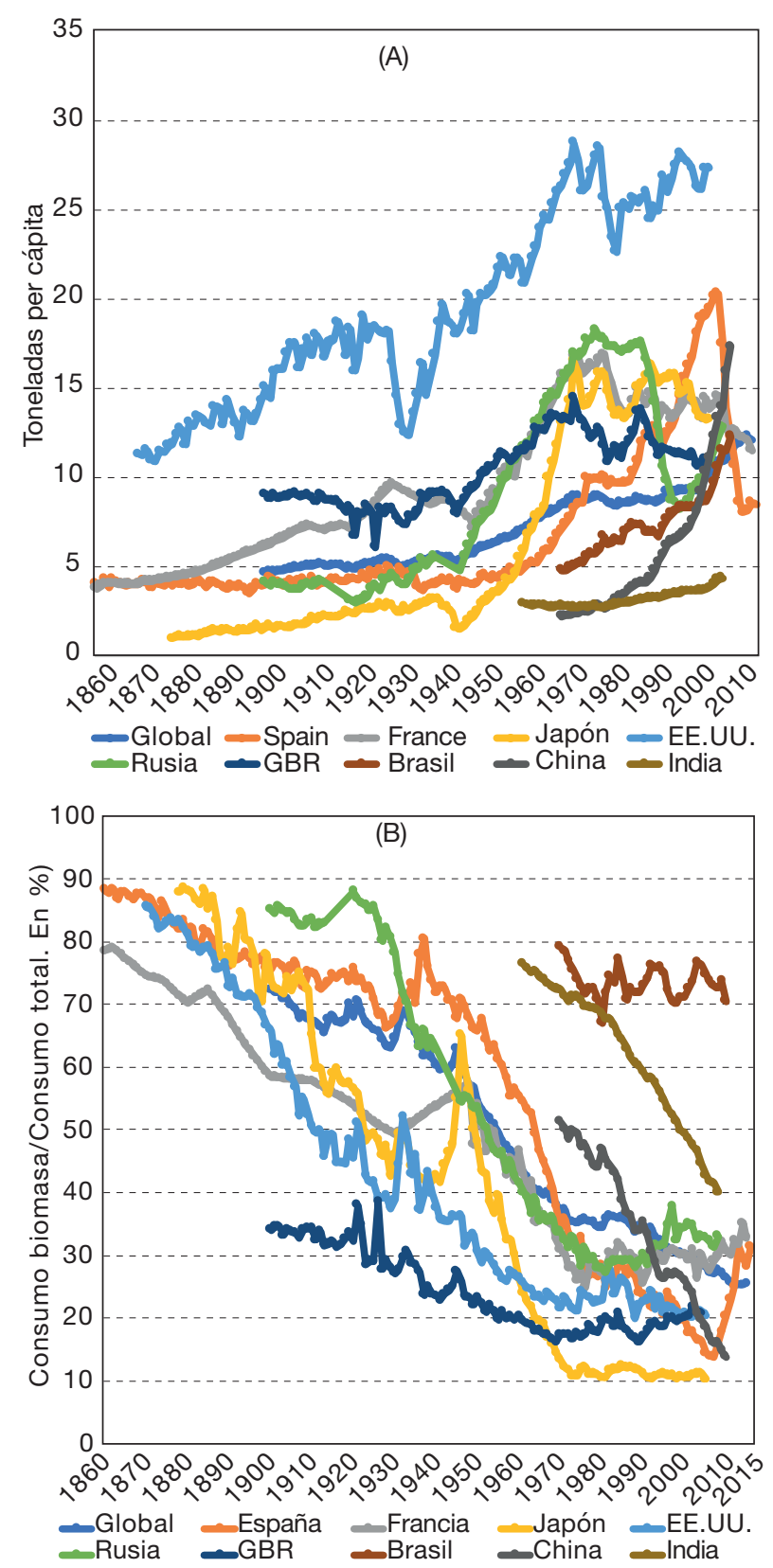

FUENTE: Elaboración propia a partir de Krausmann et al. (2009, 2011, 2016), Gierlinger et al. (2012), Magalhaes et al., (2019) y WU Vienna (2019) 


\section{GRÁFICO 6}

(C) DEL BALANCE COMERCIAL FÍSICO POR HABITANTE. (D) EVALUACIÓN DEL GRADO DE DEPENDENCIA EXTERIOR, COMPARANDO EL PORCENTAJE DE LAS IMPORTACIONES SOBRE LAS EXPORTACIONES Y EL BALANCE COMERCIAL FÍSICO POR HABITANTE CON DATOS ACUMULADOS DE 1970-2007
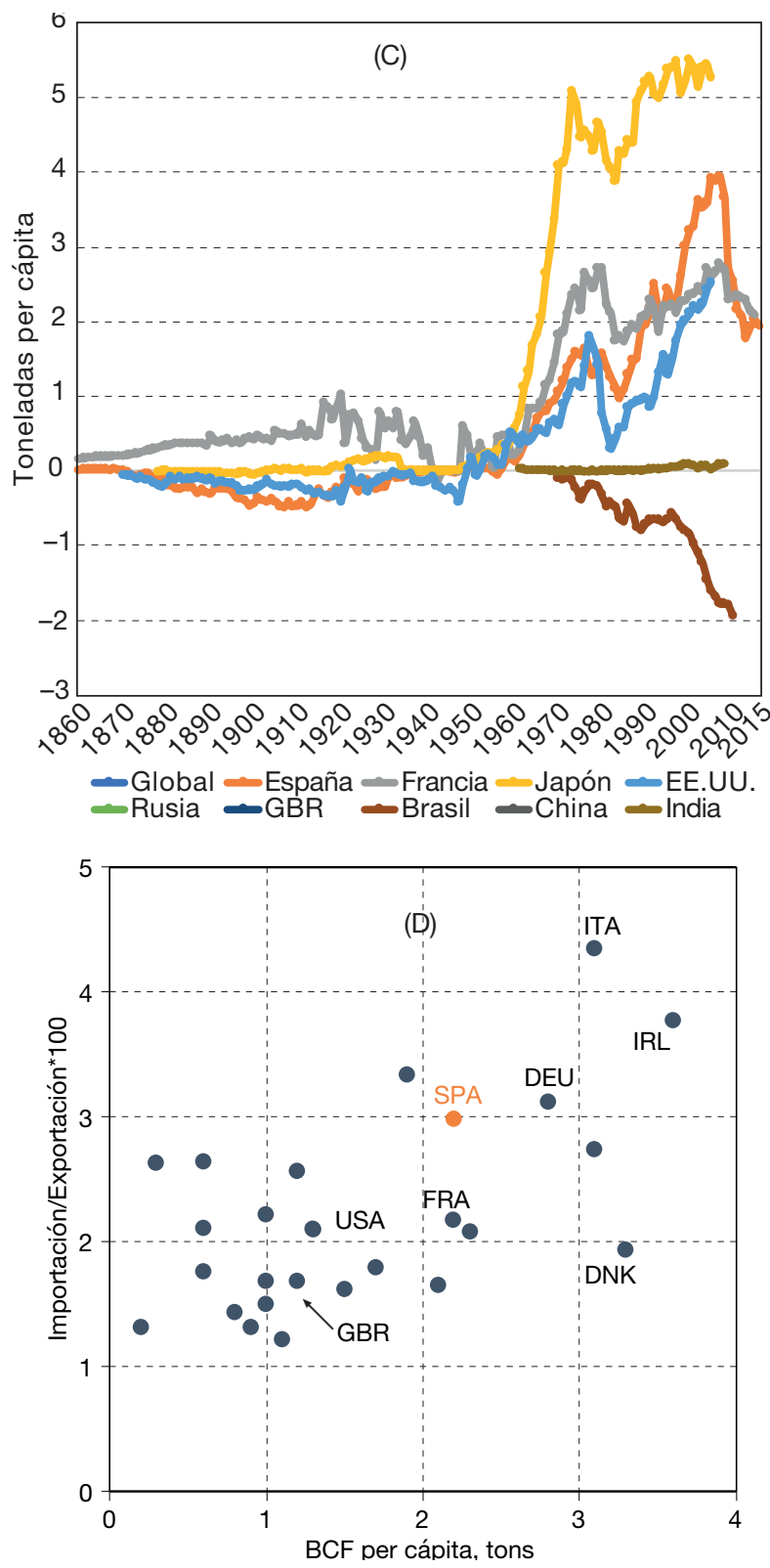

FUENTE: Elaboración propia a partir de Krausmann et al. (2009, 2011, 2016), Gierlinger et al. (2012), Magalhaes et al., (2019) y WU Vienna (2019) 


\section{Conclusiones y agenda futura de investigación}

Durante los dos últimos siglos, con diferentes ritmos e intensidad, todas las economías del mundo han protagonizado cambios sin precedentes en su metabolismo social, esto es, en la forma en la que apropian y usan energía y materiales. Estos cambios tienen en común un rápido aumento en el consumo, una transición de la biomasa a los minerales como recursos más utilizados, y un incremento en los intercambios de materiales con otros países. España, al igual que el resto de países del mundo ha seguido este patrón, si bien es cierto que con particularidades propias atribuibles a sus características geográficas y a su desarrollo histórico.

En este trabajo hemos presentado la primera serie anual de largo plazo sobre extracción, comercio y consumo de materiales por parte de la economía española entre 1860 y 2016. Los resultados obtenidos nos han permitido reconstruir y analizar las principales tendencias sobre el uso de recursos, la intensidad material de la economía, las relaciones internacionales y la cronología de la transición sociometabólica. Las conclusiones más relevantes sobre la transición española al metabolismo industrial son:

1 Un gran aumento en el uso de materiales, que pasó de 4 a 20 toneladas por habitante y año entre 1860 y 2007 . El crecimiento fue especialmente rápido entre c. 1950 y 2007, un periodo en el que España pasó de estar por debajo de la media global a tener uno de los consumos más altos del mundo.

2. Transición de la biomasa, que suponía casi el $90 \%$ de los materiales utilizados en 1860, a los recursos abióticos, que hoy representan casi el $80 \%$. Esta transición fue más tardía en España (1964) que en la mayoría de países desarrollados (siempre antes de 1950) pero anterior al de las economías emergentes.

3. España fue exportador neto de materiales, sobre todo de minerales metálicos y productos agrarios hasta $c$. 1930, pero desde $c .1950$ se convirtió en importador neto de todo tipo de materiales. De hecho, durante este último periodo aparece como uno de los principales importadores netos a nivel global, muy por encima de otros países de altas rentas.

4. Se observa una caída en la intensidad material de la economía, lo que denota un continuado proceso de desacoplamiento entre el crecimiento económico y el uso de recursos. Sin embargo, el consumo total ha seguido creciendo (hasta 2007), lo que muestra una rematerialización en términos absolutos.

5. Aunque se constatan mejoras en la eficiencia material, tanto por desarrollos tecnológicos como por cambios estructurales, el aumento en la población y, sobre todo, la mejora en la renta, han empujado al alza el consumo de recursos. 
Esta investigación, no obstante, cuenta con importantes limitaciones que deben ser abordadas en futuros trabajos de investigación.

- No existen estimaciones históricas sobre los materiales incorporados en el comercio internacional, lo que nos impide conocer la «huella material» de los países. En otras palabras, sabemos el consumo de recursos que tiene lugar «dentro» de España, pero no los consumos que son responsabilidad de los ciudadanos españoles. Estas estimaciones solo están disponibles desde 1990 gracias a los estudios input-output multirregionales, pero no para periodos anteriores.

- Dentro de los grandes agregados nacionales se esconde una gran diversidad regional en los patrones de extracción y uso de materiales. Para ofrecer un relato más preciso sobre la evolución de los niveles de vida y las responsabilidades sociales en el cambio global, es necesario descender a escalas de análisis más reducidas. Carpintero (2015) y Piñero et al. (2020) han realizado ejercicios de este tipo, pero solo para periodos recientes, por los que un reto pendiente es expandir históricamente estas estimaciones.

- Conocemos bien las dinámicas de apropiación de materiales, pero sabemos poco sobre su uso, lo cual es especialmente relevante en tres ámbitos. Por un lado, para evaluar la «circularidad» de la economía, un objetivo central dentro de la política económica actual. Una parte de los materiales extraídos se reutilizan y, por tanto, se vuelve a consumir. Por otro lado, distinguir los materiales requeridos en las fases de procesamiento y de los que realmente llegan al consumo final resulta informativo sobre los cambios en la eficiencia productiva y solo los materiales que realmente contribuyen a mejorar nuestro nivel de vida. Finalmente, para identificar qué parte del consumo se destina a stock (infraestructuras materiales que prestan servicios básicos como alojamiento o transporte) y qué parte a flujos de materiales (por ejemplo, petróleo) que tienen como objetivo mantener el stock. Estas estimaciones resultan muy importantes para diseñar sistemas más eficientes y que conduzcan a una reducción en el uso de materiales.

\section{Referencias bibliográficas}

Acosta, F., Cruz, S., \& González de Molina, M (2009). Socialismo y democracia en el campo (1880-1930). Los orígenes de la Federación Nacional de los Trabajadores de la Tierra. Ministerio de Agricultura, Pesca y Alimentación.

Ang, B. W. (2005). The LMDI approach to decomposition analysis: a practical guide. Energy Policy, 33(7), 867-871. https://doi.org/10.1016/j.enpol.2003.10.010

Ayres, R. U., \& Warr, B. (2010). The Economic Growth Engine: How Energy and Work Drive Material Prosperity. Edward Elgar Publishing.

Barbier, E. (2011). Scarcity and Frontiers: How Economies Have Developed Through Natural Resource Explotation. Cambridge University Press. 
Bolt, J., \& Van Zanden, J. L. (2014). The Maddison Project: collaborative research on historical national accounts. The Economic History Review, 67(3), 627-651. https://doi.org/10.1111/1468-0289.12032

Bruckner, M., Giljum, S., Lutz, C., \& Wiebe, K. S. (2012). Materials embodied in international trade-Global material extraction and consumption between 1995 and 2005. Global Environmental Change, 22(3), 568-576. http://dx.doi.org/10.1016/j.gloenvcha.2012.03.011

Carpintero, Ó. (2005). El metabolismo de la economía española. Fundación César Manrique.

Carpintero, Ó. (2015). El metabolismo económico regional español. FUHEM Ecosocial.

Carreras, A., \& Tafunell X. (2005). Estadísticas históricas de España, siglos XIX-XX. Fundación BBVA.

Chastagnared, G. (2017). Humos y sangre. Protestas en la cuenca de las piritas y masacre en Río Tinto (1877-1890). Universidad de Alicante.

De Bruyn, S. M., \& Opschoor, J. B. (1997). Developments in the throughput-income relationship: theoretical and empirical observations. Ecological Economics, 20(3), 255268. https://doi.org/10.1016/S0921-8009(96)00086-9

Eurostat (2018). Economy-Wide Material Flow Accounts. Handbook. Luxembourg: Publications Office of the European Union.

Ferrero, M. D. (1994). Capitalismo minero y resistencia rural en el suroeste andaluz (18731900). Universidad de Huelva.

Fischer-Kowalski, M., Krausmann, F., Giljum, S., Lutter, S., Mayer, A., Bringezu, S., \& Weisz, H. (2011). Methodology and indicators of economy-wide material flow accounting: State of the art and reliability across sources. Journal of Industrial Ecology, 15(6), 855876. https://doi.org/10.1111/j.1530-9290.2011.00366.x

García Gómez, J. J., \& Pérez Cebada, J. D. (2020). A Socio-Environmental History of a Copper Mining Company: Rio-Tinto Company Limited (1874-1930). Sustainability, 12, 4521. https://doi.org/10.3390/su12114521

Garrabou, R., \& Sanz Fernández, J. (1985). Historia agraria de la España contemporánea: expansiva y crisis (1850-1900). Crítica.

GEHR (1991). Estadísticas históricas de la producción agraria española. Ministerio de Agricultura, Pesca y Alimentación.

Gierlinger, S., \& Krausmann, F. (2012). The physical economy of the United States of America: Extraction, trade, and consumption of materials from 1870 to 2005. Journal of Industrial Ecology, 16(3), 365-377. https://doi.org/10.1111/j.1530-9290.2011.00404.x

González de Molina, G., Fernández, D. S., Casado, G. G., Infante-Amate, J., Fernández, E. A., Traver, J. V., \& Ruiz, R. G. (2020). The Social Metabolism of Spanish Agriculture, 1900-2008. Springer International Publishing.

González de Molina, M, Soto Fernández, D., \& Garrido Peña, F. (2016). Los conflictos ambientales como conflictos sociales. Una mirada desde la ecología política y la historia. Ecología Política, 50, 31-38. https://www.ecologiapolitica.info/?p=3583

González de Molina, M., García-Ruiz, R., Fernández, D. S., Guzmán, G., Cid, A., \& InfanteAmate, J. (2015). Nutrient balances and management of soil fertility prior to the arrival of chemical fertilizers in Andalusia, southern Spain. Human Ecology Review, 21(2), 23-48. http://dx.doi.org/10.22459/HER.21.02.2015.02

Graedel, T. E., Harper, E. M., Nassar, N. T., \& Reck, B. K. (2015). On the materials basis of modern society. Proceedings of the National Academy of Sciences, 112(20), 6295-6300. http://dx.doi.org/10.1073/pnas.1312752110 
Greenfield,A., \& Graedel,T.E.(2013). The omnivorous diet of modern technology. Resources, Conservation and Recycling, 74, 1-7. https://doi.org/10.1016/j.resconrec.2013.02.010

Haberl, H., Wiedenhofer, D., Pauliuk, S., Krausmann, F., Müller, D. B., \& Fischer-Kowalski, M. (2019). Contributions of sociometabolic research to sustainability science. Nature Sustainability, 2(3), 173-184. https://www.nature.com/articles/s41893-019-0225-2?proof=t

Hornborg, A. (1998). Towards an ecological theory of unequal exchange: articulating world system theory and ecological economics. Ecological Economics, 25(1), 127-136. https://doi.org/10.1016/S0921-8009(97)00100-6

Infante Amate, J., \& Iriarte Goñi, I. (2017). Las bioenergías en España. Una serie de producción, consumo y stocks entre 1860 y 2010. Sociedad Española de Historia Agraria.

Infante-Amate, J., de Molina, M. G., \& Toledo, V. M. (2017). El metabolismo social. Historia, métodos y principales aportaciones. Revibec. Revista Iberoamericana de Economía Ecológica, 27, 130-152.

https://redibec.org/wp-content/uploads/2018/01/rev27-11-corregido.pdf

Infante-Amate, J., Soto, D., Aguilera, E., García-Ruiz, R., Guzmán, G., Cid, A., \& González de Molina, M. (2015). The Spanish transition to industrial metabolism: Long-term material flow analysis (1860-2010). Journal of Industrial Ecology, 19(5), 866-876. https://doi.org/10.1111/jiec.12261

Infante-Amate, J., Urrego Mesa,A., \& Tello Aragay, E. (2020). Las venas abiertas de América Latina en la era del antropoceno: un estudio biofísico del comercio exterior (1900-2016). Diálogos Revista Electrónica de Historia, 21(2), 177-214. https://doi.org/10.15517/dre.v21i2.39736

Instituto Nacional de Estadística (2020). Cuenta de flujos de materiales. https://www.ine.es/ dyngs/INEbase/es/operacion.htm?c=Estadistica_C\&cid=1254736176943\&menu= ultiDatos\&idp $=1254735976603$

JCA, Junta Consultiva Agronómica (1891a). Avance estadístico sobre el cultivo de cereal y de leguminosas asociadas en España. Dirección General de Agricultura, Industrial y Comercio.

JCA, Junta Consultiva Agronómica (1891b). Avance estadístico sobre el cultivo y producción de la vid, junta consultiva agronómica. Dirección General de Agricultura, Industria y Comercio.

JCA, Junta Consultiva Agronómica (1891c). Avance estadístico sobre el cultivo y producción del olivo. Dirección General de Agricultura, Industria y Comercio.

Kander, A., Malanima, P., \& Warde, P. (2015). Power to the People: Energy in Europe over the Last Five Centuries. Princeton University Press.

Kander, A., Warde, P., Henriques, S. T., Nielsen, H., Kulionis, V., \& Hagen, S. (2017). International trade and energy intensity during European industrialization, 1870-1935. Ecological Economics, 139, 33-44. https://doi.org/10.1016/j.ecolecon.2017.03.042

Krausmann, F., Gaugl, B., West, J., \& Schandl, H. (2016). The metabolic transition of a planned economy: Material flows in the USSR and the Russian Federation 1900 to 2010. Ecological Economics, 124, 76-85. https://doi.org/10.1016/j.ecolecon.2015.12.011

Krausmann, F., Gingrich, S., \& Nourbakhch-Sabet, R. (2011). The metabolic transition in Japan: A material flow account for the period from 1878 to 2005. Journal of Industrial Ecology, 15(6), 877-892. https://doi.org/10.1111/j.1530-9290.2011.00376.x 
Krausmann, F., Gingrich, S., Eisenmenger, N., Erb, K. H., Haberl, H., \& Fischer-Kowalski, M. (2009). Growth in global materials use, GDP and population during the 20th century. Ecological Economics, 68(10), 2696-2705.

http://www.vegetal-e.com/fichiers/2009-krausmann-al_1469691627.pdf

Krausmann, F., Schandl, H., \& Sieferle, R. P. (2008). Socio-ecological regime transitions in Austria and the United Kingdom. Ecological Economics, 65(1), 187-201.

Krausmann, F., Schandl, H., Eisenmenger, N., Giljum, S., \& Jackson, T. (2017). Material flow accounting: measuring global material use for sustainable development. Annual Review of Environment and Resources, 42, 647-675. https://doi.org/10.1146/annurev-environ-102016-060726

Kuskova, P., Gingrich, S., \& Krausmann, F. (2008). Long term changes in social metabolism and land use in Czechoslovakia, 1830-2000: an energy transition under changing political regimes. Ecological Economics, 68(1-2), 394-407. https://doi.org/10.1016/j.ecolecon.2008.04.006

Magalhães, N., Fressoz, J. B., Jarrige, F., Le Roux, T., Levillain, G., Lyautey, M., \& Bonneuil, C. (2019). The physical economy of France (1830-2015). The history of a parasite? Ecological Economics, 157, 291-300.

Martinez-Alier, J. (2009). Social metabolism, ecological distribution conflicts, and languages of valuation. Capitalism Nature Socialism, 20(1), 58-87.

Naredo, J. M. (2003). La burbuja inmobiliario-financiera en la coyuntura económica reciente (1985-1995). Siglo XXI.

Pérez Cebada, J.D. (2014). Tierra devastada. Historia de la contaminación minera. Síntesis.

Peters, G. P. (2008). From production-based to consumption-based national emission inventories. Ecological Economics, 65(1), 13-23. https://doi.org/10.1016/j.ecolecon.2007.10.014

Pinker, S. (2018). Enlightenment Now: The Case for Reason, Science, Humanism and Progress. Penguin.

Rockström, J., Steffen, W., Noone, K., Persson, Å., Chapin III, F. S., Lambin, E., \& Nykvist, B. (2009). Planetary boundaries: exploring the safe operating space for humanity. Ecology and Society, 14(2). http://www.ecologyandsociety.org/vol14/iss2/art32/

Ruffing, K. (2007). Indicators to measure decoupling of environmental pressure from economic growth. Sustainability Indicators: A Scientific Assessment, 67, 211. https://doi.org/10.1016/j.gloenvcha.2014.03.013

Schaffartzik, A., Mayer, A., Gingrich, S., Eisenmenger, N., Loy, C., \& Krausmann, F. (2014). The global metabolic transition: Regional patterns and trends of global material flows, 1950-2010. Global Environmental Change, 26, 87-97.

Schandl, H., \& Schulz, N. (2002). Changes in the United Kingdom's natural relations in terms of society's metabolism and land-use from 1850 to the present day. Ecological Economics, 41(2), 203-221. https://doi.org/10.1016/S0921-8009(02)00031-9

Schandl, H., Fischer-Kowalski, M., West, J., Giljum, S., Dittrich, M., Eisenmenger, N., \& Krausmann, F. (2018). Global material flows and resource productivity: Forty years of evidence. Journal of Industrial Ecology, 22(4), 827-838.

https://doi.org/10.1111/jiec.12626

Sieferle, R. P. (2001). The Subterranean Forest: Energy Systems and the Industrial Revolution. White Horse Press.

Smil, V. (2016). Making the Modern World: Materials and Dematerialization. Lulu Press. 
Sudrià, C. (1997). La restricción energética al desarrollo económico de España. Papeles de Economía Española, 73, 165-188.

Tena, A. (2005). Sector exterior. En A. Carreras \& X. Tafunell, Estadísticas históricas de España, siglos XIX-XX. Fundación BBVA, pp. 573-644.

Vanwalleghem, T., Infante-Amate, J., González de Molina, M., Soto Fernández, D., \& Gómez, J. A. (2011). Quantifying the effect of historical soil management on soil erosion rates in Mediterranean olive orchards. Agriculture, Ecosystems \& Environment, 142(3-4), 341-351.

Widenhofer, D., Rovenskaya, E., Haas, W., Krausmann, F., Pallua, I., \& Fischer-Kowalski, M. (2013). Is there a 1970s syndrome? Analyzing structural breaks in the metabolism of industrial economies. Energy Procedia, 40, 182-191.

https://core.ac.uk/download/pdf/82377381.pdf

Wrigley, E. A. (2016). The Path to Sustained Growth: England's Transition from an Organic Economy to an Industrial Revolution. Cambridge University Press. http://www.materialflows.net/visualisation-centre/country-profiles

WU Vienna (2019). Country Profile for Austria. Visualisations Based Upon the UN IRP Global Material Flows Database. http://www.materialflows.net/visualisation-centre/ country-profiles 